\title{
AGE-GENDER MORTALITY STUDY ON ALCOHOL-INDUCED DEATHS IN SLOVAKIA
}

\author{
Beáta Gavurová1, Matúš Kubák², Adam Kulhánek ${ }^{1}$ \\ 'Department of Addictology, First Faculty of Medicine, Charles University and General University Hospital in Prague, Prague, Czech Republic \\ ${ }^{2}$ Faculty of Economics, Technical University of Košice, Košice, Slovak Republic
}

\section{SUMMARY}

Objective: Alcohol use is one of the ten most common risk factors threatening global health that is avoidable (ranked fifth after smoking). It is involved in high rates of liver cirrhosis, epilepsy, hypertension, cerebrovascular and mental illness. Negative consequences of family and social drinking are also very significant. The aim of the study is to quantify the gender and age-differentiated disparities in alcohol-related mortality in the population over 16 years between the years 1996-2017 in Slovakia.

Methods: We used data from mortality reports within 1996-2017 provided by the National Health Information Centre in the Slovak Republic. We applied two-dimensional correspondence analysis where dimensions are age and chosen causes of deaths induced by use of alcohol and classified by the International Classification of Diseases.

Results: In case of males, we found that K74 - Fibrosis and cirrhosis of liver diagnosis almost perfectly corresponds to age 66-75 years, and we documented strong correspondence between K70 - Alcoholic liver disease and age $46-55$ years. For females, the most robust finding is that K70 - Alcoholic liver disease corresponds relatively similarly with age groups $26-35,36-45,46-55$. The results of the analysis allow us to obtain a detailed overview of the development of mortality in individual alcohol diagnoses and their intervention in individual age groups by gender. Mortality for some diagnoses affects the young female as well as male population. We observed that there are systematic differences in alcohol-induced mortality between males and females.

Conclusions: In such development of the alcohol-related mortality structure, the priority remains the permanent provision of primary, secondary and tertiary prevention at the individual and population level. The results of our analysis represent a valuable platform for health and social policymakers to develop quality national and regional health strategies aimed at eliminating the consequences of alcohol use. Lessons learned from our analysis will be supported by our other geographically oriented analytical lines to link identified and quantified regional disparities in the mortality of alcohol diagnoses to the availability of health care to treat these diseases.

Key words: alcohol, age, gender, alcohol-related mortality, significant regional disparities, correspondence analysis

Address for correspondence: B. Gavurová, First Faculty of Medicine, Charles University and General University Hospital in Prague, Apolinářská 4, 12800 Prague 2, Czech Republic. E-mail: beata.gavurova@lf1.cuni.cz

https://doi.org/10.21101/cejph.a5765

\section{INTRODUCTION}

Central and Eastern Europe is one of the centres of the global epidemic of excessive alcohol consumption. Excessive alcohol consumption leads to serious health problems. Besides mental disorders, it is usually accompanied by many physical injuries and illnesses. Alcohol is a legal psychoactive substance and its drinking belongs to traditional culture in many countries, which greatly complicates primary prevention processes. Primary prevention is often underestimated due to reliance on effective medical treatment (1). According to the Statistical Office of the Slovak Republic, alcohol consumption in 2017 was the lowest since 2003. According to WHO data, alcohol consumption in Slovakia was comparable to other countries. In 2017, alcohol consumption of 8.2 litres was recorded, in 2016 it was 8.4 litres. In the early 1990s, consumption exceeded 10 litres per capita. In 2017, the consumption of both spirits and wines decreased, but beer consumption increased. In the neighbouring Czech Republic, alcohol consump- tion is rising, even among children. There is also criticism directed at the Czech government, which does not address this issue (2). If we were to evaluate drug and alcohol strategies in Europe, we would find a significant conceptual heterogeneity in the form of different models. For example, the absence of a national strategy, the existence of a strategy for illegal drugs but absent for alcohol, the existence of separate strategies for drugs and alcohol, two interlinked strategies and a policy document on illegal drugs and alcohol. So far, there is no clear inclination to one of the models, although, as the European Commission states, many countries have already adopted, in addition to their drug strategy, alcohol, some have expanded the content of drug policy documents (3). One of the effective options is also to develop a separate alcohol strategy within each country. The absence of a common European system and trends encourage governments to take into account several aspects in developing concepts related to the use of legal and illicit drugs. This issue is also strongly related to analysis and evaluation of the availability of addiction treatment, with 
marked disparities among approaches across Europe. Attention is drawn to the inaccessibility of treatment, especially for those who need it most (3). These disparities are not only geographic inaccessibility but a wide range of other socioeconomic factors that should be the subject of specific research by international research teams (4-6). These facts led to the realization of our research aiming to quantify the gender and age-differentiated disparities in alcohol-related mortality in the population over 16 years during the period 1996-2017 in Slovakia.

\section{Overview of International Research Results}

Many foreign research studies investigate the relationship between alcohol use and mortality - induced or affected by it. Authors do not study usually the influence of alcohol use separately but in consistency with other risk factors. Interestingly, their emphasis is on regional health disparities, as well as on gender and age differences as important determinants of the relevance of mortality trends. Chen et al. (7) in their study looked at mortality rates due to oncological diseases in relation to risk factors. The research platform consisted of 978 monitoring sites in 31 provinces in China. The authors examined 23 risk factors in several categories (e.g., smoking, occasional smoking, drinking alcohol, physical inactivity, etc.). The results of the analysis confirmed significant regional disparities in different mortality rates for oncological diseases due to the risk factors examined. The authors highlight the importance of effective primary strategies for cancer prevention and particular political attention to the factors that had the greatest impact on mortality. Greenfield et al. (8) focused on examining the relationship between the use of alcohol, tobacco and drugs in relation to gender, institution, age and cultural engagement among the young population - students of the Native American community college and university. The survey sample consisted of 347 students. Alcohol use was examined through the number of drinks in 30 days. As the findings show, over $43 \%$ of students used alcohol during the study month, $27 \%$ were alcohol-abusive, $20 \%$ were drugged, and $13 \%$ were smokers at the same time. Younger people also used marijuana in the last month. A study by Barrios et al. (9) explicitly linked the influence of alcohol use and the prevalence of tobacco smoking to oncological diseases. According to the authors, oesophageal cancer (code C15) shows significant geographical differences and is one of the leading causes of cancer deaths worldwide. Data on mortality for the analysis was used from the WHO database. The results of the study call for the development of effective policies to control tobacco and alcohol consumption. Specific proposals for prevention programmes to eliminate oesophageal cancer in various geographic areas of Central and South America were suggested, and other risk factors, e.g., unhealthy diet, obesity, etc., were also specified. Another study by Saint Onge and Krueger (10) focused on risk factors and regional health disparities, with their target population being adults aged $18+$. The database consisted of representative national data from the US for the period 2004-2009 from the National Health Interview Survey (NHIS). The authors identify 7 behavioural patterns based on lifestyle risk factors: alcohol use, smoking, physical activity, influenza vaccination, doctor visits, and more. They report significant racial/ethnic, gender, regional, and age differences in defined research groups. According to the authors, the specification of such restricted groups will have a significant impact on the investigation of future mortality relationships. The authors also intend to link the results of their analysis to sociological theories of health behaviour as well as to several interventions aimed at improving health of the population. Hadland et al. (11) in their study examined the relationship between the strength of alcohol policies at the national level and the rate of alcohol-related cirrhosis mortality. The Alcohol Policy Scale (APS) and Validated Assessment of Policies by 50 US States and Washington DC were used to quantify the effectiveness and implementation of 29 policies. The results of their analysis point to the significant disparities in the states in terms of alcohol cirrhosis mortality and the different impact of policies. The highest mortality was found in men living in Western states and in states with a high proportion of American Indians. Higher APS scores were associated with a lower mortality rate in women than in men. In subsequent research studies the authors would like to look into the root causes of racial, ethnic and regional differences in alcohol-related mortality separately in both genders. The younger age group is the research topic of Beard et al. (12). The authors compared patterns in high-risk alcohol use and smoking in the regions of England and their impact on socio-demographic characteristics. The survey sample consisted of 53,922 adults aged 16 and over who participated in the Alcohol and Smoking Toolkit Studies. The research was conducted between 2014 and 2016. The study's results point to regional differences in smoking, but not in high-risk drinking, which the authors explain by the impact of socio-demographic differences. The association of risk drinking and alcohol use with mortality was also investigated by Bea et al. (13). The authors looked at women's mortality from breast cancer and tried to reveal regional differences. Female mortality in South Carolina was 40\% higher for African Americans than for European Americans. In view of this considerable racial inequality, the authors examined the use of alcohol and tobacco in an ethnically diverse nationwide study of women with newly diagnosed invasive breast cancer. The study is based on self-reported behavioural data. The results of the study showed a high risk of developing breast cancer caused by risky drinking and smoking. Thus, targeted prevention programmes focusing on specific diagnoses are needed. Gender differentiation in relation to oncological diseases caused by excessive drinking, smoking, unhealthy lifestyle and other factors was examined by Elias et al. (14). Data from the Canadian Community Health Survey and the Manitoba and First Nations Regional Longitudinal Health Survey were the database. First Nations are the largest group in Canada, which accounts for up to $64 \%$ of the native population. This group had markedly high-risk factors - alcohol abuse, high smoking rates, obesity, diabetes, and lack of physical activity. Based on the study results, a very heavy burden of cancer in the First Nations population living on reserve is expected in the future. The results of the study call for interventions using partnerships between health and social authorities and pressures for long-term institutional partnerships. The study criticizes the government's priority interest in addressing economic inequalities, not inequalities in health. Zanjani et al. (15) examined the impact of concomitant use of alcohol and medicines in adults aged 50 years and over on the development of hospitalization. They used electronic records of acute hospitalizations of adults aged over 50 for the period 2001-2012. The results have shown an increase in hospitalization due to alcohol and medication 
use among older adults. Higher increase in hospitalizations was recorded in rural areas in adults aged 65 and over. For urban residents, high hospitalization was recorded in population aged 50-64. These results call for prevention programmes and public health policies aimed at better education and coping with alcohol consumption in older adult patients.

In this study, we examined the measure of correspondence between the age category and selected causes of death induced by excessive use of alcohol. The symmetrical normalisation method and chi-square distance measure were used. We split our analysis into two parts, correspondence analysis of male mortality and correspondence analysis of female mortality.

\section{MATERIALS AND METHODS}

Our dataset contains all deceased persons aged over 16 years because of excessive use of alcohol in the Slovak Republic within the period from 1996 to 2017. Information about deceased individuals was obtained from death certificates. The data were provided by the National Health Information Centre of the Slovak Republic. We were looking for the following diagnosis: F10 - Acute alcohol intoxication, G31 - Degeneration of nervous system due to alcohol, G62 - Alcoholic polyneuropathy, I42 - Cardiomyopathy, K29 - Alcoholic gastritis, K70 - Alcoholic liver disease, K73 - Chronic hepatitis, not elsewhere classified, K74 - Fibrosis and cirrhosis of liver, K86 - Alcohol-induced chronic pancreatitis. We divided age into relatively homogenous intervals. Those intervals are 16-25, 26-35, 36-45, 46-55, 56-65, 66-75, 76-85, and 85+ years.

To process data and to achieve the research objective we decided to apply correspondence analysis $(16,17)$. Correspondence analysis is a descriptive (exploratory) technique for analysing tables with two or more entries. Correspondence analysis gives us certain measures of correspondence between rows and columns of the pivot table. Correspondence analysis is multidimensional visual technic that allows us to graphically display rows and columns of the pivot table and specify the measure of correspondence between the rows and columns. The provided results are similar to results provided by factor analysis techniques and allow us to explore the structure of the categorical variables of the table. The output of correspondence analysis is 2-dimensional graph. Coordinates in graph are analogous to factors in a principal component analysis. This method uses nominal variables as inputs. The necessary condition for correspondence analysis use is the existence of dependence between the observed data. We exclude from correspondence analysis age interval 16-25 years, because it would devalue our results because of underrepresentation of these observations (only 130 persons of this age died because of excessive alcohol use). Data were processed using IBM SPSS $\AA$ software.

\section{RESULTS}

Table 1 summarizes the situation within the group of observed diagnosis. In total, there were 34,493 deaths caused by alcohol during the mentioned period. We can state that there are $72 \%$ of deaths in males. According to Table 1, the majority of deaths occur in age interval 56-65 years, but also age between 46-55 years is critical.

Figure 1 depicts the differences between genders in alcoholinduced mortality for the four most risky diagnoses which caused $95 \%$ of all deaths among observed diagnoses. With an obvious predominance, K70 - Alcoholic liver disease, K74 - Fibrosis and cirrhosis of liver cause the majority of all deaths related to excessive alcohol use.

We can state that in term of $\mathrm{K} 70$ - Alcoholic liver disease and I42 - Cardiomyopathy males die three times more often than females and in case of K74 - Fibrosis and cirrhosis of liver and K86 - Alcohol-induced chronic pancreatitis males die more than two times more often than females. Figure 2 reveals some interest-

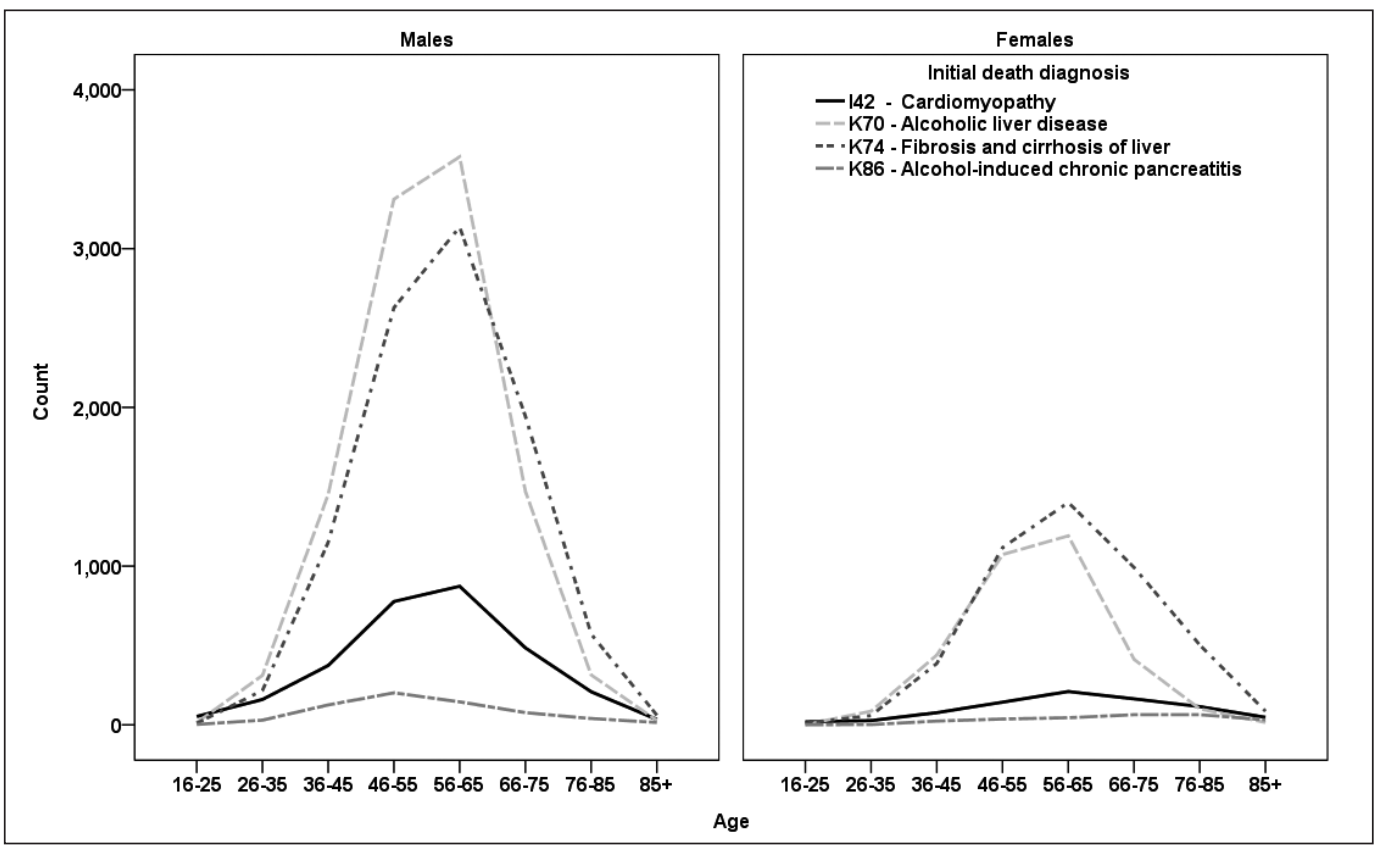

Fig. 1. Distribution of mortality, $K 70, K 74,142, K 86$ among age groups $(N=34,493)$. 
Table 1. Age distribution of deaths within time period 1996-2017 (N=34,493)

\begin{tabular}{|c|c|c|c|c|c|c|c|c|c|}
\hline \multirow{2}{*}{ Gender/Initial death diagnosis } & \multicolumn{8}{|c|}{ Age } & \multirow{2}{*}{ Total } \\
\hline & $16-25$ & $26-35$ & $36-45$ & $46-55$ & $56-65$ & $66-75$ & $76-85$ & $85+$ & \\
\hline \multicolumn{10}{|l|}{ Males } \\
\hline F10 - Acute alcohol intoxication & 0 & 8 & 28 & 47 & 73 & 13 & 3 & 0 & 172 \\
\hline G31 - Degeneration of nervous system due to alcohol & 3 & 9 & 18 & 52 & 59 & 63 & 29 & 9 & 242 \\
\hline G62 - Alcoholic polyneuropathy & 1 & 0 & 1 & 10 & 8 & 12 & 3 & 0 & 35 \\
\hline 142 - Cardiomyopathy & 53 & 160 & 374 & 777 & 873 & 485 & 209 & 34 & 2,965 \\
\hline K29 - Alcoholic gastritis & 3 & 3 & 11 & 35 & 37 & 38 & 39 & 16 & 182 \\
\hline K70 - Alcoholic liver disease & 15 & 312 & 1,453 & 3,312 & 3,578 & 1,471 & 315 & 28 & 10,484 \\
\hline K73 - Chronic hepatitis, not elsewhere classified & 2 & 11 & 46 & 98 & 119 & 103 & 28 & 12 & 419 \\
\hline K74 - Fibrosis and cirrhosis of liver & 10 & 217 & 1,150 & 2,628 & 3,136 & 1,944 & 572 & 61 & 9,718 \\
\hline K86 - Alcohol-induced chronic pancreatitis & 3 & 30 & 126 & 202 & 145 & 77 & 40 & 15 & 638 \\
\hline Total & 90 & 750 & 3,207 & 7,161 & 8,028 & 4,206 & 1,238 & 175 & 24,855 \\
\hline \multicolumn{10}{|l|}{ Females } \\
\hline F10 - Acute alcohol intoxication & 0 & 1 & 4 & 9 & 14 & 0 & 1 & 1 & 30 \\
\hline G31 - Degeneration of nervous system due to alcohol & 4 & 2 & 13 & 34 & 66 & 37 & 47 & 34 & 237 \\
\hline G62 - Alcoholic polyneuropathy & 1 & 3 & 3 & 3 & 8 & 8 & 3 & 0 & 29 \\
\hline 142 - Cardiomyopathy & 19 & 27 & 77 & 143 & 210 & 164 & 115 & 48 & 803 \\
\hline K29 - Alcoholic gastritis & 1 & 0 & 3 & 7 & 18 & 30 & 75 & 44 & 178 \\
\hline K70 - Alcoholic liver disease & 2 & 86 & 440 & 1,073 & 1,191 & 413 & 101 & 15 & 3,321 \\
\hline K73 - Chronic hepatitis, not elsewhere classified & 0 & 2 & 16 & 36 & 52 & 60 & 33 & 14 & 213 \\
\hline K74 - Fibrosis and cirrhosis of liver & 12 & 59 & 387 & 1,117 & 1,401 & 992 & 504 & 86 & 4,558 \\
\hline K86 - Alcohol-induced chronic pancreatitis & 1 & 2 & 24 & 37 & 45 & 64 & 64 & 32 & 269 \\
\hline Total & 40 & 182 & 967 & 2,459 & 3,005 & 1,768 & 943 & 274 & 9,638 \\
\hline \multicolumn{10}{|l|}{ Total } \\
\hline F10 - Acute alcohol intoxication & 0 & 9 & 32 & 56 & 87 & 13 & 4 & 1 & 202 \\
\hline G31 - Degeneration of nervous system due to alcohol & 7 & 11 & 31 & 86 & 125 & 100 & 76 & 43 & 479 \\
\hline G62 - Alcoholic polyneuropathy & 2 & 3 & 4 & 13 & 16 & 20 & 6 & 0 & 64 \\
\hline 142 - Cardiomyopathy & 72 & 187 & 451 & 920 & 1,083 & 649 & 324 & 82 & 3,768 \\
\hline K29 - Alcoholic gastritis & 4 & 3 & 14 & 42 & 55 & 68 & 114 & 60 & 360 \\
\hline K70 - Alcoholic liver disease & 17 & 398 & 1,893 & 4,385 & 4,769 & 1,884 & 416 & 43 & 13,805 \\
\hline K73 - Chronic hepatitis, not elsewhere classified & 2 & 13 & 62 & 134 & 171 & 163 & 61 & 26 & 632 \\
\hline K74 - Fibrosis and cirrhosis of liver & 22 & 276 & 1,537 & 3,745 & 4,537 & 2,936 & 1,076 & 147 & 14,276 \\
\hline K86 - Alcohol-induced chronic pancreatitis & 4 & 32 & 150 & 239 & 190 & 141 & 104 & 47 & 907 \\
\hline Total & 130 & 932 & 4,174 & 9,620 & 11,033 & 5,974 & 2,181 & 449 & 34,493 \\
\hline
\end{tabular}

ing facts. We use boxplots for our analysis. The bottom of the box indicates the 25 th percentile. It means that $25 \%$ of observations are situated below this cut point. The top of the box represents the 75 th percentile, thus $25 \%$ of observations have values above the 75 th percentile. It follows that $50 \%$ of the observations should lie within the box. The first obvious fact is that in all groups of observed diagnosis the median age (dark line in the boxes) of death is lower for males than for females. It means that half of the cases have a value greater than the median, and half have a value lower. Concerning the variation of age of death within the boxes, thus in $50 \%$ of cases, we find the lowest dispersion in case of F10 - Acute alcohol intoxication, K70 - Alcoholic liver disease and K74 - Fibrosis and cirrhosis of liver. The largest dispersion can be found in the case of G31 - Degeneration of nervous system due to alcohol, K29 - Alcoholic gastritis and K86 - Alcohol-induced chronic pancreatitis. We can also observe that those whiskers (Tbars that extend from the boxes) in case of males are in majority of diagnoses (except G62 - Alcoholic polyneuropathy and I42 - Cardiomyopathy) lower than in females, i.e. the minimal age of death is lower in males. If we suppose that data are normally distributed, we should expect that $95 \%$ of the data lie between the whiskers. If we focus our analysis on extreme values - outliers, thus points under and above whiskers, we can state that diagnoses with a minimum number of extreme values are F10 - Acute alcohol intoxication, G62 - Alcoholic polyneuropathy, K73 - Chronic hepatitis, not elsewhere classified, and K86 - Alcohol-induced 
chronic pancreatitis. In case of G31 - Degeneration of nervous system due to alcohol, both genders reach bottom outliers. In the case of I42 - Cardiomyopathy, both genders reach bottom outliers, but in case of males, we observe some upper outliers. In the case of K70 - Alcoholic liver disease and K74 - Fibrosis and cirrhosis of liver, most risky diagnoses among observed ones, we observe equally distributed bottom and upper outliers for both genders.

\section{Male Mortality}

One of the necessary conditions of correspondence analysis use is the assumption of dependence between the observed variables. To verify whether there is significant relationship between two nominal variables, we performed the Pearson's chi-square test of independence.

We can find the p-value of Pearson's chi-square test in Chisquare column in Table 2. We reject the null hypothesis of nondependence of data and we suppose that there is the dependence between data. Table 2 also shows the proportion of inertia captured by our model. Table 2 tells us also that our model captures $89 \%$ of total inertia. The first dimension contributes by $68.3 \%$ of inertia and second dimension contributes by $20.7 \%$ of inertia, what makes in total $89 \%$ of inertia. Total inertia is a measure that characterizes the quality of transformation of multidimensional points in the correspondence map. Our model is seen as satisfactory, as it captures $89 \%$ of inertia.

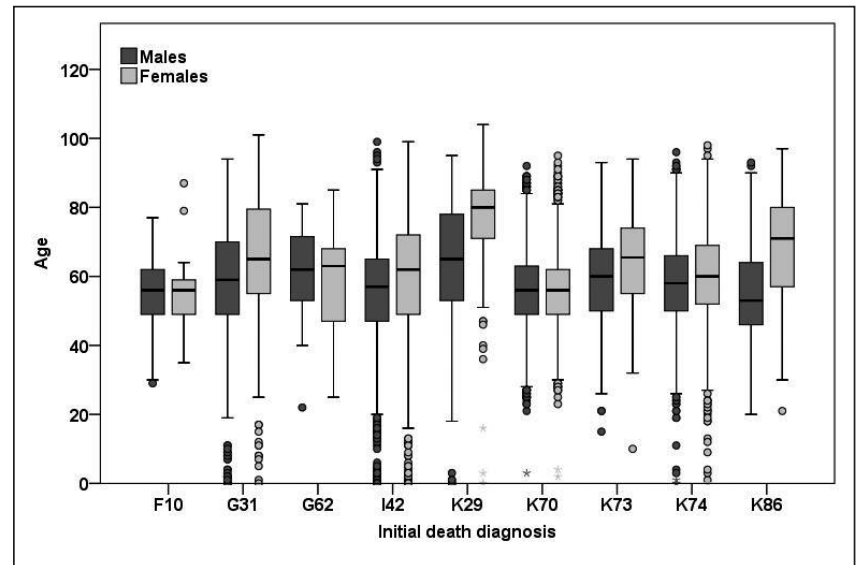

Fig. 2. Boxplot: Age/Gender/Diagnosis.
Figure 3 contains the results of correspondence analysis for males. We can see on correspondence map that in case of males, K29 - Alcoholic gastritis is corresponding to age $85+$. Further, we have only one outlying diagnosis, which does not correspond with any age interval in case of males. This diagnosis is G62 Alcoholic polyneuropathy.

There is a relatively close relationship between age interval 76-85 years and G31 - Degeneration of nervous system due to alcohol and K73 - Chronic hepatitis, not elsewhere classified diagnosis in case of males. Diagnose K74 - Fibrosis and cirrhosis of liver diagnosis is almost perfectly related to age 66-75 years and slightly related to age interval 56-65 years. We find perfect correspondence between $\mathrm{K} 70$ - Alcoholic liver disease and age interval 46-55 years and lighter correspondence of this disease with age intervals 56-65 years and 36-45 years. K86 - Alcohol-induced chronic pancreatitis corresponds to relatively young males aged 26-35 years. It seems that F10 - Acute alcohol intoxication could correspond to age interval $36-45$ years.

\section{Female Mortality}

Here we again excluded age interval 16-25 years from our analysis, because it would devalue our results because of underrepresentation of these observations. To verify whether there is significant relationship between two nominal variables, we perform the Pearson's chi-square test of independence. P-value

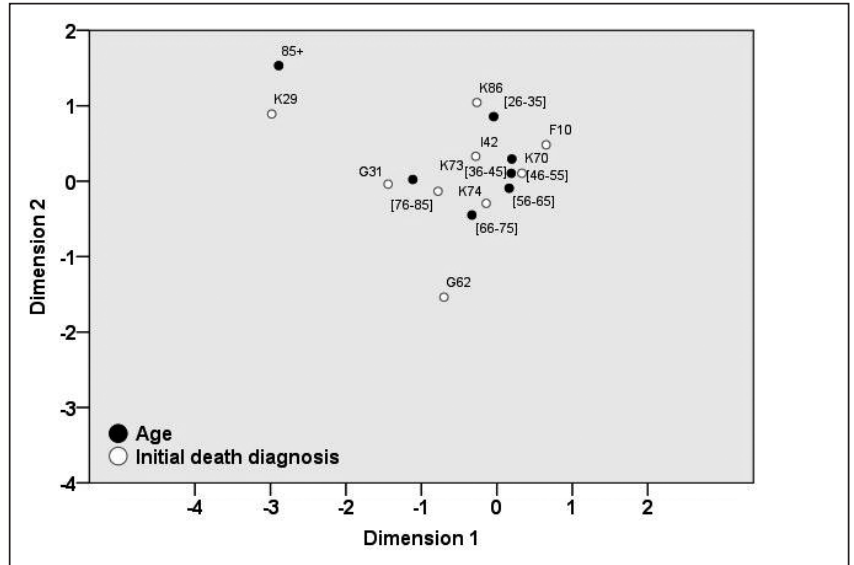

Fig. 3. Correspondence analysis: Age/Initial death diagnosis/ Males.

Table 2. Proportion of inertia - males

\begin{tabular}{|c|c|c|c|c|c|c|c|c|}
\hline \multirow[b]{2}{*}{ Dimension } & \multirow{2}{*}{$\begin{array}{l}\text { Singular } \\
\text { value }\end{array}$} & \multirow[b]{2}{*}{ Inertia } & \multirow[b]{2}{*}{ Chi-square } & \multirow[b]{2}{*}{$p$-value } & \multicolumn{2}{|c|}{ Proportion of inertia } & \multicolumn{2}{|c|}{ Confidence singular value } \\
\hline & & & & & $\begin{array}{l}\text { Accounted } \\
\text { for }\end{array}$ & Cumulative & SD & $\begin{array}{c}\text { Correlation } \\
2\end{array}$ \\
\hline 1 & 0.164 & 0.027 & & & 0.683 & 0.683 & 0.010 & 0.231 \\
\hline 2 & 0.090 & 0.008 & & & 0.207 & 0.890 & 0.007 & \\
\hline 3 & 0.051 & 0.003 & & & 0.066 & 0.957 & & \\
\hline 4 & 0.031 & 0.001 & & & 0.025 & 0.982 & & \\
\hline 5 & 0.021 & 0.000 & & & 0.011 & 0.993 & & \\
\hline 6 & 0.017 & 0.000 & & & 0.007 & 1.000 & & \\
\hline Total & & 0.039 & 973.609 & $<0.001$ & 1.000 & 1.000 & & \\
\hline
\end{tabular}

Numbers in bold indicate statistically significant values. 
of Pearson's chi-square test in Table 3 is $<0.001$, thus we reject the null hypothesis of non-dependence of data and we suppose that there is the dependence between data. Table 3 also shows the proportion of inertia captured by our model. Table 3 includes the information about total inertia of the model. Total inertia is a measure that characterizes the quality of transformation of multidimensional points in the correspondence map. In case of females, it captures $96.3 \%$ of total inertia. The first dimension contributes by $84.9 \%$ of inertia and the second dimension contributes by $11.4 \%$ of inertia.

Figure 4 is the correspondence map of analysis for females. Here again, as it was in case of males K29-Alcoholic gastritis diagnosis and age interval $85+$ forms outlying corresponding couple. Next, we identified two diagnoses, which are not corresponding to any age interval in case of females. Those diagnoses are F10 - Acute alcohol intoxication and G31 - Degeneration of nervous system due to alcohol. K86 - Alcohol-induced chronic pancreatitis corresponds to age interval $76-85$ years. K73 - Chronic hepatitis, not elsewhere classified has light correspondence with age intervals 66-75 years and 76-85 years. Age interval 66-75 years is also corresponding with diagnoses G62 - Alcoholic polyneuropathy and K74 - Fibrosis and cirrhosis of liver. Further, we find cloud of relatively similar age intervals. Those intervals are 26-35, $36-45,46-55$ and 56-65 years. Those age intervals correspond more or less with $\mathrm{K} 70$ - Alcoholic liver disease.

\section{DISCUSSION}

In the context of the main goal of the contribution, our basic analytical trajectories were oriented to investigate gender and age differences in the mortality of the Slovak population. The reason for identifying gender disparities was the fact that the female organism is more susceptible to the same amount of alcohol, and the consequences of its use are much more serious in women. For example, women have higher body fat, lower body weight, lower water content, smaller liver (burdened with hormone processing) - liver steatosis, liver cirrhosis, greater metabolism of hormones, fewer enzymes, etc. Alcoholism in women also results in many allergies, psoriasis, premature menopause, breast cancer, development of associated psychological problems, bulimia, often combining alcohol and drugs, and more rapidly causing brain damage. The impact of alcohol on the development of related

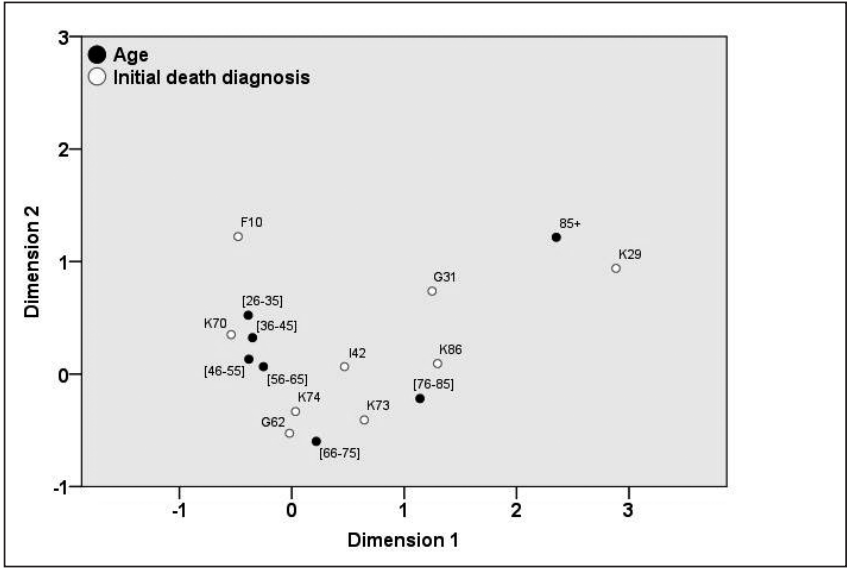

Fig. 4. Correspondence analysis: Age/Initial death diagnosis/ Females.

diseases is different between genders. For example, liver cirrhosis occurs in men after approximately 10-20 years of consuming daily 132 grams of alcohol, in women for about 5 years using daily 52 grams of alcohol (18). Female alcoholics are giving birth to injured children about 3 to 3.5 times more often than women whose partners are drinking. World statistics mapping alcohol consumption and liver cirrhosis mortality indicate an alarming trend in alcohol consumption and increase in prevalence and mortality related to cirrhosis. The incidence and prevalence of other ethyl toxic diseases also increase. This trend is striking since the 1950s (19). In countries with the highest alcohol consumption, the diseases are the third most common disease in cardiovascular and oncological diseases (20).

These results from epidemiological studies can also be supported by the outputs of our analysis, where we found compatible but also incompatible developmental mortality rates of diagnoses in the examined gender. Diagnosis K29 - Alcoholic gastritis corresponds to men aged $85+$ as in case of women, where this diagnosis and age interval form a correspondent and remarkable couple. Diagnosis G62 - Alcoholic polyneuropathy in men does not correspond to any age range but for women aged 66-75 years. In women in any age range there are no diagnoses of F10 - Acute alcohol intoxication and G31 - Nervous system degeneration due to alcohol use. This diagnosis of G31 in men has a relatively narrow relationship between 76-85 years of age, as has K73Chronic hepatitis, a non-classified diagnosis in men. In women,

Table 3. Proportion of inertia - females

\begin{tabular}{|c|c|c|c|c|c|c|c|c|}
\hline \multirow[b]{2}{*}{ Dimension } & \multirow{2}{*}{$\begin{array}{c}\text { Singular } \\
\text { value }\end{array}$} & \multirow[b]{2}{*}{ Inertia } & \multirow[b]{2}{*}{ Chi-square } & \multirow[b]{2}{*}{$p$-value } & \multicolumn{2}{|c|}{ Proportion of inertia } & \multicolumn{2}{|c|}{ Confidence singular value } \\
\hline & & & & & $\begin{array}{l}\text { Accounted } \\
\text { for }\end{array}$ & Cumulative & SD & $\begin{array}{c}\text { Correlation } \\
2\end{array}$ \\
\hline 1 & 0.367 & 0.135 & & & 0.849 & 0.849 & 0.012 & 0.415 \\
\hline 2 & 0.134 & 0.018 & & & 0.114 & 0.963 & 0.011 & \\
\hline 3 & 0.064 & 0.004 & & & 0.026 & 0.989 & & \\
\hline 4 & 0.032 & 0.001 & & & 0.006 & 0.995 & & \\
\hline 5 & 0.027 & 0.001 & & & 0.005 & 1.000 & & \\
\hline 6 & 0.007 & 0.000 & & & 0.000 & 1.000 & & \\
\hline Total & & 0.159 & $1,522.346$ & $<0.001$ & 1.000 & 1.000 & & \\
\hline
\end{tabular}

Numbers in bold indicate statistically significant values 
K73 - Chronic hepatitis, a non-classified light correspondence with age ranges of 66-75 years and 76-85 years was found. Diagnosis K74 - Fibrosis and liver cirrhosis in men is almost perfectly related to the age of 66-75 years and is easily related to the age range of 56-65 years. Even in women, K74 diagnosis corresponds to the age range of 66-75 years, but in addition to this interval, we also found a cloud of similar age brackets in women 26-35, $36-45,46-55,56-65$. It is a very unfavourable fact indicating an intervention of many age groups of the population. This is also confirmed by the mortality rate of the diagnosis K70 - Alcoholic liver disease in men, where there is a perfect correspondence with the age range of 46-55 years and a mild correspondence with age range of 56-65 years and 36-45 years. K86 - Chronic alcoholinduced pancreatitis corresponds to relatively young men aged 26-35 years, while women are affected by this diagnosis in the age range of 76-85 years. In men F10 - Acute alcohol intoxication may correspond to the age range of 36-45 years. As can be seen from these results, we obtained a detailed overview of mortality trends for individual alcohol diagnoses and their impact on individual age groups by gender. It is striking that mortality from some diagnoses affects the young population, women as well as men. Due to specificities of the diseases diagnosed, their symptoms, the nature and duration of treatment, and the age when the disease occurs, it is possible to create concepts of differentiated prevention programmes to eliminate the impact of alcoholism on individuals, families and the whole society. Lessons learned from our analysis will be supported by other analytical lines, geographically oriented, to link quantified regional disparities in the age and gender differentiation of alcohol diagnoses, with the availability of health care, which is very pronounced in Europe. This would also encourage a higher rate of primary, secondary and tertiary prevention.

There are limitations of the study since we analysed the death certificates what brings some biases. Firstly, the population of drinkers avoid regular medical check-ups, especially in the rural areas of Central Europe they are underdiagnosed. Secondly, if diagnosed with cardiomyopathy, it may not be written in the patient documentation with this diagnosis as the first diagnosis (but as I500 - Heart failure, or common comorbidity I259 - Ischaemic heart disease). Thirdly, even if correctly diagnosed, it may be forgotten by the general practitioner or coroner completing the death certificate (this document is often written with minimal knowledge of the patients' history, especially in case of alcohol/ drug abuse).

\section{CONCLUSION}

Excessive alcohol consumption is a worldwide problem and, according to the WHO, is the third in the world, and second in the European ranks of avoidable mortality. In the Central and Eastern European countries, every fifth man dies at the age of 65 due to alcoholism. In Slovakia, there is currently no accurate evidence of deaths directly caused by alcohol intoxication, estimates suggest hundreds of lethal poisonings. Alcohol consumption is increasing worldwide. Although the treatment processes are constantly improving, these activities need to be perceived as a phase out of alcoholism. In these processes, it is necessary to cooperate with the whole society and to constantly form public opinion.
Prevention programmes based on a high quality analytical and data platform play a significant role. This is conditioned by the use of appropriate methodologies to detect the causal link between the variables examined. We applied a correspondence analysis to achieve the goal of our study. The aim of the study was to quantify gender- and age-differentiated disparities in alcohol-related mortality in the population over 16 years during the years 1996-2017 in Slovakia. Data from the National Health Information Centre was used. Correspondence analysis has highlighted significant gender disparities in the mortality of multiple alcohol-related diagnoses and made it possible to specify age groups burdened by individual diagnoses. It will help to health and social policymakers to better understand the importance of creating and applying targeted, age-based and gender-differentiated prevention programmes. In the development of alcohol-related mortality structure, the priority remains the permanent provision of primary, secondary and tertiary prevention at the individual as well as population level.

\section{Acknowledgements}

Our thanks go out to the National Health Information Centre of the Slovak Republic along with the Statistical Office of the Slovak Republic for providing access to the central mortality database for the studied period as well as the other associated data. Our acknowledgments also belong to the Ministry of Health of the Slovak Republic for its cooperation in the creation of the new conceptions and methodologies and for its support of our research activities.

\section{Funding}

This paper was supported by the GCDPC, Grant No. A-86-19 and by the institutional support programme Progress No. Q06/LF1.

\section{Conflict of Interests}

None declared

\section{REFERENCES}

1. Okruhlica L, Kantorková A. Alcohol addiction and its treatment [Internet]. Bratislava: National Health Information Centre; 2016 [cited 2019 Sep 22]. Available from: https://www.npz.sk/sites/npz/Stranky/NpzArticles/2013_06/Zavislost_od_alkoholu_a_jej_liecba.aspx?did=2\&sdid $=5$ $4 \&$ tuid $=0$ \&page $=$ full\&. (In Slovak.)

2. Kučerová T. Alcohol consumption in Czech Republic is increasing. Only Lithuanians drink more than Czechs [Internet]. Prague: iDNES; 2018 [cited 2019 Sep 22]. Available from: https://www.idnes.cz/ekonomika/ domaci/alkohol-cesi-piji-alkohol-oecd.A180720_150136_ekonomika_ kuce. (In Czech.)

3. European Monitoring Center for Drugs and Drug Addiction. The state of the drugs problem in Europe: annual report 2010. Luxembourg: Publications Office of the European Union; 2010.

4. Gavurová B, Koróny S, Barták M. The prevalence and perception of drinking among full-time Slovak University students in relation to socioeconomic determinants. Adiktologie. 2017;17(2):92-106. (In Slovak.)

5. Gavurová B, Tóth P, Barták M, Petruželka B. Preventable mortality caused by the use of alcohol in Slovakia - a regional and socio-economic perspective. Adiktologie. 2018;18(2):73-80.

6. Petruželka B, Barták M, Rogalewicz V, Popov P, Gavurová B, Dlouhý M, et al. Alcohol use and related problems among students of social work at selected universities in the Czech Republic and Slovakia - a pilot study of risky periods. Adiktologie. 2017;17(2):108-17. (In Czech.)

7. Chen W, Xia C, Zheng R, Zhou M, Lin C, Zeng H, et al. Disparities by province, age, and sex in site-specific cancer burden attributable to 23 potentially modifiable risk factors in China: a comparative risk assessment. Lancet Glob Health. 2019;7(2):PE257-69. 
8. Greenfield BL, Venner KL, Tonigan JS, Honeyestewa M, Hubbell H, Bluehorse D. Low rates of alcohol and tobacco use, strong cultural ties for Native American college students in the Southwest. Addict Behav. 2018;82:122-28.

9. Barrios E, Sierra MS, Musetti C, Forman D. The burden of oesophageal cancer in Central and South America. Cancer Epidemiol. 2016;44 Suppl $1:$ S53-61.

10. Saint Onge JM, Krueger PM. Health lifestyle behaviors among US adults. SSM Popul Health. 2017;3:89-98.

11. Hadland SE, Xuan Z, Blanchette JG, Heeren TC, Swahn MH, Naimi TS. Alcohol policies and alcoholic cirrhosis mortality in the United States. Prev Chronic Dis. 2015;12:150200. doi: 10.5888/pcd12.150200.

12. Beard E, Brown J, West R, Angus C, Kaner E, Michie S. Healthier central England or North-South divide? Analysis of national survey data on smoking and high-risk drinking. BMJ Open. 2017;7(3):e014210. doi: 10.1136/bmjopen-2016-014210.

13. Bea VJ, Cunningham JE, Alberg AJ, Burshell D, Bauza CE, Knight KD, et al. Alcohol and tobacco use in an ethnically diverse sample of breast cancer patients, including sea island African Americans: implications for survivorship. Front Oncol. 2018;8:392. doi: 10.3389/fonc.2018.00392.

14. Elias B, Kliewer EV, Hall M, Demers AA, Turner D, Martens P, et al. The burden of cancer risk in Canada's indigenous population: a comparative study of known risks in a Canadian region. Int J Gen Med. 2011;4:699709.
15. Zanjani F, Smith R, Slavova S, Charnigo R, Schoenberg N, Martin C, et al. Concurrent alcohol and medication poisoning hospital admissions among older rural and urban residents. Am J Drug Alcohol Abuse. 2016;42(4):422-30.

16. Benzécri JP. L'Analyse des Données. Volume 2: L'Analyse des Correspondances. Paris: Dunod; 1973.

17. Hirschfeld HO. A connection between correlation and contingency. Mathematical Proceedings of the Cambridge Philosophical Society. 1935;31(4):520-4.

18. Bobrovská M. Alcohol and women [Internet]. 2019 [cited 2019 Sep 22]. Available from: http://www.ruvzmartin.sk/poradna/Alkohol_zavislot/ Alkohol zeny.pdf. (In Slovak.)

19. Szántová M, Kupčová V, Bada V, Goncalvesová E. Trends in alcohol consumption in relation to liver diseases in Slovakia 1973-1994. Bratisl Lek Listy. 1997;98(1):12-6. (In Slovak.)

20. Richter G. Alkoholsmissbrauch und seine medizinischen Folgen. Pharmedicum. 1994;(3):18-20.

Received March 15, 2019 Accepted in revised form September 22, 2019 